\title{
PERFIL DO ZINCO FRENTE AO ESTADO NUTRICIONAL DE INDIVÍDUOS COM TUBERCULOSE PULMONAR
}

\section{ARTIGO DE REVISÃO}

SÁ, Adriana da Silva Nogueira ${ }^{1}$

SÁ, Adriana da Silva Nogueira. Perfil do zinco frente ao estado nutricional de indivíduos com Tuberculose Pulmonar. Revista Científica Multidisciplinar Núcleo do Conhecimento. Ano 05, Ed. 04, Vol. 05, pp. 33-50. Abril de 2020. ISSN: 2448-0959, Link de acesso: https://www.nucleodoconhecimento.com.br/nutricao/perfil-do-zinco

\section{RESUMO}

A tuberculose, doença que afeta a humanidade há muito tempo, é ocasionada por bactérias da espécie Mycobacterium tuberculosis. Milhões de pessoas são acometidas por essa enfermidade, segundo a Organização Mundial de Saúde, sendo os países subdesenvolvidos os locais de mais ocorrências. No Brasil, 70 mil indivíduos são infectados e 4,6 mil morrem a cada ano. Como forma de tratamento, o zinco tem se mostrado importante para a defesa imunológica. Estudos epidemiológicos demonstram que o uso de medicamentos e a suplementação do zinco aumentam a resistência às infecções. Assim, dada a relevância do conhecimento científico acerca desse mineral, o objetivo do presente artigo é promover a discussão acerca das evidências do perfil de zinco frente ao estado nutricional de indivíduos com tuberculose pulmonar. Para tanto, metodologicamente, foi realizada uma revisão da literatura com base em artigos que abordam tal tema. Consideramos, desse modo, os estudos de Téllez (1994); Balck (1998); Shankar (1998); Baum (2000); Fraker (2000); Hambidge (2000); Food and Nutrition Board (2001); Hotz et al. (2003); Mafra (2004); Fernandes e Mafra (2005); Barbosa et al. (2010); Bockor (2010) e Lorena (2011).

\footnotetext{
${ }^{1}$ Especialista em Nutrição Clínica.
} 
Palavras-chave: Tuberculose, estado nutricional, zinco, avaliação bioquímica, carência de nutrientes.

\section{INTRODUÇÃO}

A tuberculose é uma enfermidade causada por uma bactéria que afeta inicialmente os pulmões. Todavia, é necessário um olhar bastante atento a essa doença, pois, seu agravo atinge outros órgãos do corpo humano e pode levar a óbito em poucos dias (MACIEL et al., 2012). De acordo com Nogueira (2006), a cada ano, 8,4 milhões de pessoas são acometidas pela doença ao redor do globo e, desse total, morrem aproximadamente 2 milhões de indivíduos.

Apesar de existir no Brasil há mais de um século, a tuberculose ainda representa atualmente um problema crítico de saúde pública. O percentual de registro de casos é muito alto no país. Segundo dados da Organização Mundial da Saúde (OMS), por ano, 70 mil brasileiros são infectados e 4,6 mil morrem, o que faz com que o Brasil ocupe $017^{\circ}$ lugar dentre os 22 países representantes dos $80 \%$ de casos da doença. (OMS, 2013).

Como forma de tratamento, evidências epidemiológicas demonstram que o uso de medicamentos e a suplementação do zinco aumentam a resistência às infecções (PEDERSEN e TOFT, 2000). Estudos realizados ao longo de várias décadas indicam que tal mineral apresenta efeitos sobre os marcadores de imunidade (Pedersen e Toft, 2000; Cordova e Alvarez-Mon, 1995), dentre os quais, o desenvolvimento normal e funcional de células imunes - como, por exemplo, os neutrófilos, linfócitos T e as células natural killer - e a produção de citocinas (SHANKAR e PRASAD, 1998).

No entanto, constata-se, ao longo dos últimos anos, a ingestão deficitária de zinco tanto nos países desenvolvidos quanto nos em desenvolvimento. As causas para tal problema nutricional são diversas: ingestão de agentes que comprometem a absorção do mineral; consumo abaixo dos valores dietéticos recomendados e aumento da excreção urinária. Como consequências, o indivíduo apresenta alterações nas respostas imunes, anorexia, perda de peso, alopecia, diarreia e tuberculose. 
Tendo tudo isso em vista, o objetivo do presente estudo é discutir a evidência científica do perfil de zinco frente ao estado nutricional de indivíduos com tuberculose pulmonar. Tal temática de pesquisa se mostra relevante por se tratar de uma problemática que acomete o Brasil desde o início da colonização e que acarreta altas taxas de morbimortalidade e alto custo socioeconômico para o tratamento.

No que concerne à metodologia, foi empreendida uma revisão da literatura. Para tanto, foram coletados e interpretados artigos que tratassem de evidências científicas do perfil de zinco frente ao estado nutricional de indivíduos com tuberculose pulmonar. Assim, consideramos os trabalhos de Téllez (1994); Balck (1998); Shankar (1998); Baum (2000); Fraker (2000); Hambidge (2000); Food and Nutrition Board (2001); Hotz et al. (2003); Mafra (2004); Fernandes e Mafra (2005); Barbosa et al. (2010); Bockor (2010) e Lorena (2011).

O presente estudo está dividido em seções. Na próxima, será apresentada detalhadamente a metodologia adotada para condução da pesquisa. Já na segunda, será feita uma apreciação e exposição qualitativa e quantitativa dos resultados obtidos. Por fim, serão sintetizadas as principais conclusões obtidas ao longo da seção anterior.

\section{METODOLOGIA}

Para o desenvolvimento desta pesquisa, foram selecionados, num primeiro momento, artigos que tratassem das evidências científicas do perfil de zinco frente ao estado nutricional de indivíduos com tuberculose pulmonar. Posteriormente, realizou-se a interpretação do material coletado por meio da análise temática de Bandin, composta por três etapas, segundo Minayo (2010):

- leitura dos artigos para a impregnação do conteúdo e constituição do corpus, o que valida a abordagem qualitativa;

- exploração do material tendo em vista as unidades de registro por meio de expressões e palavras significativas para classificar e agregar, de forma 
organizada e sistemática, os dados no alcance do núcleo de compreensão do texto e

- com a articulação dos estudos, obtenção como unidade temática "o conhecimento científico gerado nas produções do perfil de zinco em indivíduos com tuberculose pulmonar".

Em resumo, realizou-se uma revisão da literatura que abarcou artigos que tratassem do perfil do zinco no organismo de indivíduos acometidos por tuberculose pulmonar.

\section{DISCUSSÃO DOS DADOS}

Passado um século, a tuberculose ainda é um grande desafio para o Brasil que, segundo a Organização Mundial de Saúde, contabiliza 70 mil infectados por ano. Nogueira (2006, apud LEÃO, SANTOS JUNQUEIRA, MACHADO, 2008, p. 1)[2] confirma o exposto, mas indica uma quantidade diferente de pessoas acometidas pela doença: "Conhecida como 'o mal do século XIX' a tuberculose definitivamente não é uma doença do passado. Ao contrário, ela é a maior causa de morte por doença infecciosa em adultos em todo o mundo. O Brasil tem 118 mil novos casos por ano".

Já mundialmente, 6 milhões de pessoas são infectadas e dessas mais de um milhão morrem por ano. (BRASIL, 2019). Dentre os fatores para as mortes, arrolam-se os seguintes: a desigualdade social e seus determinantes, o advento da AIDS, a multirresistência do bacilo causador da moléstia, o envelhecimento da população e os movimentos migratórios (MACIEL et al., 2012).

Segundo o Ministério da Saúde, a tuberculose é uma doença infecciosa, cuja causa é a bactéria Mycobacterium tuberculosis ou Bacilo de Koch (BK), que, apesar de afetar prioritariamente os pulmões, torna vulnerável os demais órgãos, como os rins, os ossos e as meninges. Além disso, é transmissível, majoritariamente, por via aérea, em especial, pela inalação de gotículas com os bacilos, oriundas de tosse, fala ou espirro de pessoas infectadas (BRASIL, 2019). 
Quanto às alterações no metabolismo, pode-se observar uma ampla e complexa resposta à infecção, que inclui febre, leucopenia, proteólise muscular, uso impróprio dos substratos metabólicos e síntese hepática de proteínas relacionadas à fase aguda. Como consequência, gera-se aumento nos processos de gliconeogênese e lipogênese, o que acarreta diminuição da síntese de albumina e, por conseguinte, desnutrição e emagrecimento.

Nessa perspectiva, o estado nutricional do paciente acometido por tuberculose necessita de uma atenção especial, pois é comprometido não só pela doença, mas também pelo tratamento farmacológico (METCALFE, 2004). Isso porque, o esquema de tratamento pode contribuir para efeitos colaterais, como má absorção de nutrientes, vômitos, dor abdominal, hepatotoxicidade, inapetência e diarreia, que influenciam no consumo alimentar e, consequentemente, na perda de peso.

Desde o início do século $X X$, a tuberculose era relacionada à má nutrição e à pobreza. Atualmente, segundo Nogueira (2006), sabe-se que esses dois fatores estão associados direccionalmente. Isso porque o indivíduo que não apresenta uma boa alimentação está mais distante do que é considerável saudável e, por conseguinte, corre risco de contrair a infecção. Na direção oposta, quando infectado, o indivíduo pode exibir défices nutricionais, conforme detalhou-se acima. Nos termos de Talon e Pereira (2010, p. 110):

Perda de massa magra e perda de reserva de gordura, além da ativação de citocinas e do metabolismo anormal de proteínas, mas a desnutrição também é um fator de risco para o desenvolvimento da doença. De tal forma, que a incidência é maior entre indivíduos com peso abaixo dos limites de normalidade, que têm prejuízo da função imune, aumentando a susceptibilidade e a morbidade

Da mesma forma, pessoas em situação de vulnerabilidade social geralmente estão expostas a precárias condições de higiene e, por conseguinte, podem ser infectadas. Em contrapartida, uma vez contaminadas, a falta de higiene pode resultar em 
imunossupressão e, consequentemente, em infecção por micro-organismos oportunistas.

Assim, o organismo necessita estar em perfeita harmonia, ou seja, para manter o corpo nutrido, é preciso que haja boa saúde, pois, do contrário, uma baixa na imunidade gera efeitos diretamente nos aportes nutricionais, aumentando ainda mais a gravidade da enfermidade (BOCKOR, 2010).

Todavia, cabe ressaltar que a alimentação por si não basta para determinar uma vida saudável. É preciso um bom funcionamento metabólico para a absorção dos nutrientes ingeridos, sendo o zinco uma substância fundamental nesse processo. Segundo Mafra (2004), longos períodos de défices desse mineral podem acarretar:

Anorexia - pelo aumento dos níveis de norepinefrina e alterações no hipotálamo; Retardo no crescimento e defeito no crescimento fetal; Cicatrização lenta; Intolerância à glicose pela diminuição de produção de insulina; Hipogonadismo, impotência sexual e atrofia dos ovários ou testículos; Atraso na maturação sexual e esquelética; Restrição da utilização de vitamina A; Fragilidade osmótica dos eritrócitos; Disfunções imunológicas, ocorrendo infecções intercorrentes; Hipogeusia - o Zn é componente da gustina, uma proteína envolvida com o paladar; Desordens de comportamento, aprendizado e memória; Diarréia, dermatite e ALOPECIA.

Hambidge (2000, p. 130) observa a seguinte correlação entre níveis de ingestão de zinco e países em desenvolvimento:

A deficiência de zinco moderada, além da grave, tem sido cada vez mais detectada, principalmente nos países em desenvolvimento, onde estudos bem delineados têm mostrado a importância clínica deste estado de deficiência, onde se observa: retardo no crescimento, diarreia, pneumonia, malária e prejudicado desenvolvimento cerebral. 
A baixa quantidade de zinco no organismo pode ser decorrente de diversos fatores, como pequeno consumo da substância, ingestão de filatos e fibras que reduzem a biodisponibilidade daquele mineral, nutrição parenteral total, insuficiência renal crônica, desnutrição energético-protéica etc. Na tabela abaixo, são apresentados os pontos de corte de zinco sérico, usados para diagnosticar a deficiência dessa substância no organismo:

Tabela 1: Pontos de corte para zinco sérico.

Tabela 1. Pontos de corte para zinco sérico.

\begin{tabular}{|c|c|c|}
\hline Estágios de vida & Zn soro (feminino) $(\mu \mathrm{g} / \mathrm{dL})$ & Zn soro (masculino) $(\mu \mathrm{g} / \mathrm{dL})$ \\
\hline$<10$ anos* & 64 & 65 \\
\hline$>10$ anos $* *$ & 70 & 74 \\
\hline$>65$ anos** & 72 & 72 \\
\hline \multicolumn{3}{|c|}{ Gestação } \\
\hline Primeiro trimestre** & 56 & - \\
\hline Segundo trimestre** & 50 & - \\
\hline Terceiro trimestre** & 50 & - \\
\hline \multicolumn{3}{|c|}{ Mulheres com uso de anticoncepcionais } \\
\hline $20-44$ anos $* *$ & 65 & - \\
\hline
\end{tabular}

Fonte: Hotz et al. (2003, apud COMINETTI; COZZOLINO; REIS, 2017, p. 18).

Para pessoas sadias, segundo a Food and Nutrition Board (2001), recomenda-se a ingestão de $8 \mathrm{mg}$ de zinco por dia para mulheres e $11 \mathrm{mg}$ por dia para homens. Tal mineral encontra-se em diferentes proporções nos alimentos, dos quais mariscos, ostras, carnes vermelhas, fígado, miúdos e ovos são consideradas as melhores fontes, ao passo que nozes e leguminosas são fontes relativamente boas.

O zinco, juntamente com outras substâncias, desempenha um importante papel no sistema de defesa antioxidante, cuja função é obstar e/ou diminuir os danos causados por radicais livres ou espécies reativas não radicais. Para tanto, pode-se impedir a formação desses agentes (sistemas de prevenção) e/ou a sua ação (sistemas de varredores) e/ou favorecer a reconstituição das estruturas biológicas afetadas. Nas palavras de Barbosa et al. (2010, p. 633): 
Os antioxidantes são definidos como qualquer substância que, presente em menores concentrações que as do substrato oxidável, seja capaz de atrasar ou inibir a oxidação deste de maneira eficaz. Tais substâncias podem agir diretamente, neutralizando a ação dos radicais livres e espécies não-radicais, ou indiretamente, participando dos sistemas enzimáticos com tal capacidade.

O sistema de defesa antioxidante também se divide em enzimático e não enzimático que, no caso do último tipo, é composto por vários antioxidantes de proveniência endógena ou dietética. Na tabela abaixo, extraída do estudo de Barbosa et al. (2010), estão elencados alguns desses antioxidantes e sua ação sobre o organismo:

Tabela 2: Ações e mecanismos de algumas substâncias antioxidantes.

Tabla 2. Acciones y mecanismos de diversas sustancias antioxidantes.

\begin{tabular}{|c|c|c|}
\hline Antioxidantes & Acción & Referencia \\
\hline \multicolumn{3}{|c|}{ No enzimáticos (de origen dietético) } \\
\hline Vitamina A ( $\beta$-caroteno) & Protección contra la oxidación de lípidos y ADN & 23 \\
\hline Vitamina C (ácido ascórbico) & $\begin{array}{l}\text { Inhibición de las EROs (agente reductor). Estimula el } \\
\text { poder antioxidante de la vitamina E y selenio. Pro- } \\
\text { tección contra los daños causados por la LDL-ox }\end{array}$ & 23 \\
\hline Vitamina $\mathrm{E}$ ( $\alpha$-tocoferol) & $\begin{array}{l}\text { Protección contra la peroxidación de los ácidos gra- } \\
\text { sos insaturados de la membrana celular y de las LDL. } \\
\text { Convierte } \mathrm{O}_{2}^{*} \text { y } \mathrm{H}_{2} \mathrm{O}_{2} \text { en formas menos reactivas }\end{array}$ & 23 \\
\hline $\mathrm{Cu}, \mathrm{Zn}, \mathrm{Mn}, \mathrm{Se}$ & $\begin{array}{l}\text { Cofactores de las enzimas antioxidantes SOD-Cu/Zn, } \\
\text { SOD-Mn y GSH-Pox }\end{array}$ & \\
\hline Otros carotenoides (licopeno) & $\begin{array}{l}\text { Protección contra la oxidación de lípidos, LDL, pro- } \\
\text { teínas y ADN. Secuestro e inactivación de radicales } \\
\text { libres }\end{array}$ & 38 \\
\hline $\begin{array}{l}\text { Fitoquímicos (resveratrol, cate- } \\
\text { quinas, quercetinas, ácidos fenó- } \\
\text { licos y otros) }\end{array}$ & Protección contra la oxidación de lípidos y ADN & 25 \\
\hline \multicolumn{3}{|l|}{ Enzimáticos } \\
\hline SOD & $\begin{array}{l}\text { SOD-Cu/Zn (citosol), SOD-Mn (mitocondria). Catáli- } \\
\text { sis de la conversión de } \mathrm{O}_{2}^{\cdot} \text { en } \mathrm{H}_{2} \mathrm{O}_{2}\end{array}$ & 6 \\
\hline Cat & 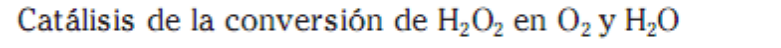 & 6 \\
\hline GSH-Pox & Catálisis de la reducción de $\mathrm{H}_{2} \mathrm{O}_{2}$ a $\mathrm{H}_{2} \mathrm{O}$ & 6 \\
\hline
\end{tabular}

No caso de pacientes com tuberculose, o estado nutricional do zinco é prejudicado devido a uma maior demanda metabólica pelo mineral, o que compromete a imunidade, a fagocitose e outros processos de resposta do organismo (TÉLLEZ, 1994; 
BOCKOR, 2010). Com a deficiência dessa substância, o prognóstico do indivíduo com tuberculose pulmonar piora, porque o infectado passa a carecer de um nutriente antioxidante. Segundo Fernandes e Mafra (2005, p. 147):

O zinco é essencial também para a função normal do sistema imunológico, sendo que na sua deficiência pode ocorrer, atrofia tímica, linfopenia, diminuição das mitoses, de imunoglobulina, entre outras alterações. Na deficiência de zinco ocorrem danos na barreira mucosa do trato gastrointestinal e pulmonar, aumentando assim, a susceptibilidade a infecções

Com isso, agravam-se as complicações do estresse oxidativo, o que culmina no aumento das citocinas referentes a processos inflamatórios e, por conseguinte, há maior degradação energética e, principalmente, proteica. Ademais, tal quadro resulta em aumento do processo de apoptose, influenciando diretamente na imunidade do indivíduo. A título de elucidação e síntese, consideremos o esquema metabólico abaixo:

Figura 1: Relação do zinco com o estresse oxidativo e processo inflamatório.

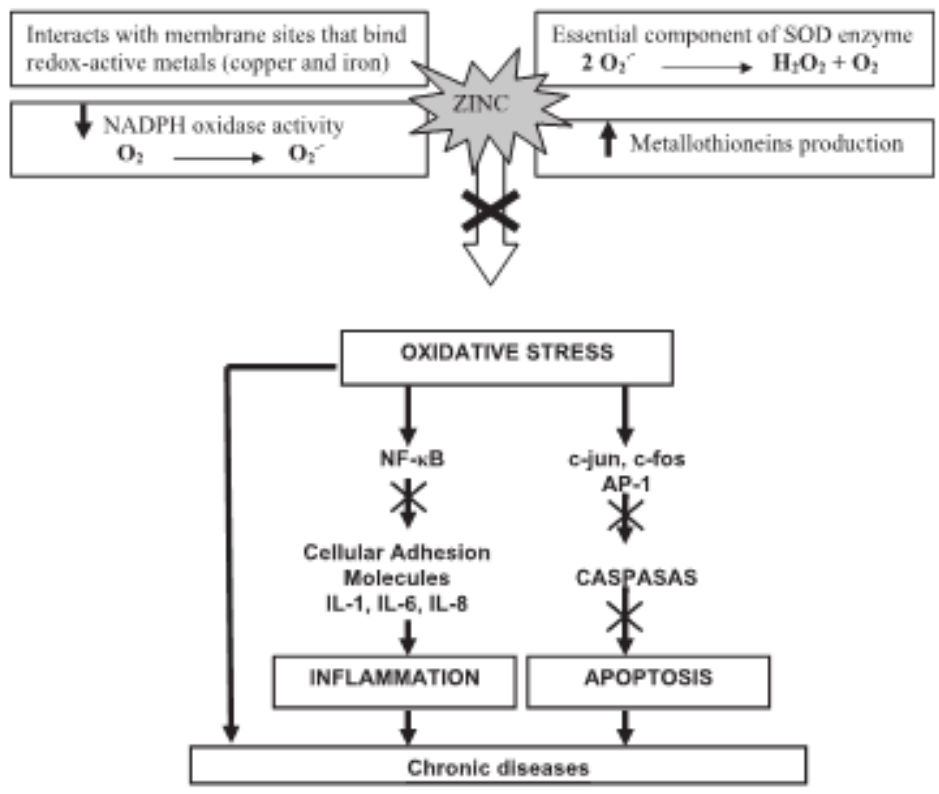

Fonte: LORENA (2011, p. 394). 
Segundo Fraker (2000), vários estudos demonstram que o zinco afeta o sistema imunológico desde a pele até a regulação das células brancas presentes no sangue, responsáveis pela defesa do organismo. Além disso, tal mineral influencia os mecanismos de defesa específicos e não específicos do organismo humano.

Como exemplos de mecanismos do segundo tipo, citemos a fagocitose - processo de ingestão e destruição de elementos estranhos ao nosso organismo, que é realizado por macrófagos, eosinófilos etc. - e a ação nos neutrófilos e das células natural killer, todos regulados pelo zinco. (SHANKAR, 1998). Como exemplos de mecanismos de defesa específicos, podem ser citadas a imunidade humoral - produção de anticorpos pelos linfócitos $\mathrm{B}$ para destruição de antígenos (como vírus e bactérias) - e a mediada por células - produção de linfócitos $T$ que, juntamente com proteínas especiais, eliminam micro-organismos e células anormais -, ambos também influenciados pelo zinco. Nas palavras de Fraker (2000, p. 742): "O zinco é necessário para a ativação da timulina, um hormônio que estimula o desenvolvimento de células brancas em linfócitos T com funções específicas ('auxiliares', 'supressores' e 'matadores')."

Pesquisas também demonstram que o défice de zinco aumenta o risco de doenças infecciosas, congênitas ou adquiridas. Assim, a regulação precoce do nível de zinco no organismo reabilita o sistema imunológico e permite a eliminação da infecção (BAUM, 2000). Por exemplo, Balck (1998) relata que a suplementação do mineral reduz a ocorrência, duração e a gravidade de infecções respiratórias agudas e diarreias. Já Baum (2000) indica que os portadores de HIV, vulneráveis a défices de zinco, obstam a progressão da doença e aumentam a resistência a outros tipos de infecções quando submetidos a ingestão adequada daquela substância.

Com base na exposição feita ao longo dessa seção, conclui-se que o estado nutricional do indivíduo acometido pela tuberculose é fundamental não só para o diagnóstico como também para o prognóstico. Por exemplo, a pessoa em condições de vulnerabilidade social, quando infectada, geralmente chega ao hospital com o estado nutricional debilitado, necessitando de uma equipe multiprofissional que atenda o sujeito em todas as suas particularidades para se alcançar o sucesso no tratamento (BRASIL, 2006). 
Assim, o diagnóstico precoce é uma das formas mais eficazes para o bom tratamento e prognóstico da doença. Com essa finalidade, o governo brasileiro elaborou, em 2010, o Programa Nacional de Controle da Tuberculose (PNCT), cujo objetivo é diagnosticar e tratar prontamente os casos a fim de garantir a cura. É um trabalho organizado pelos serviços de saúde do SUS, especialmente, aqueles da Atenção Básica, que lidam diretamente com o indivíduo (BRASIL, 2019).

O primeiro sinal da doença é a aparição de tosse (seca ou com catarro) por mais de três semanas consecutivas. Nesse caso, mesmo estando ausentes outros sintomas, é necessário que o indivíduo seja submetido ao exame de baciloscopia (escarro) (BIAGOLI, 2008). Esse exame, realizado nas Unidades Básica de Saúde (UBS), é gratuito e o resultado é rápido, sendo informado em poucos dias. Quando o resultado é positivo, a própria UBS inicia o tratamento medicamentoso, sempre assistido por um médico. O êxito no tratamento depende do paciente, que deve seguir corretamente o que foi prescrito e usar os medicamentos pelo tempo previsto, geralmente por seis meses. Quando o paciente interrompe os cuidados por conta própria, diminuem-se as chances de cura e aumenta-se a probabilidade de a doença ressurgir de forma mais resistente.

\section{CONSIDERAÇÕES FINAIS}

A tuberculose, apesar de ser uma enfermidade que afeta o Brasil desde o início da colonização, ainda se faz bastante presente na atualidade. Dessa maneira, o conhecimento científico sobre a doença é de grande importância para o tratamento e para a diminuição do número de mortes.

Concluímos que o zinco é essencial para a manutenção da imunidade por meio de mecanismos diretos e indiretos. Estudos realizados com seres humanos de diversas idades e com défices de zinco demonstram que a suplementação do mineral gerou efeitos positivos sobre o sistema imunológico, aumentando a resistência a infecções por bactérias e controlando casos de diarreias e infecções respiratórias. 
A literatura indica que a suplementação de zinco deve se dar, especialmente, entre populações de risco de tuberculose, levando em conta o sexo, a idade, o estado de saúde e as dosagens máximas permitidas. Todavia, é necessária a realização de pesquisas complementares para se conhecer de modo aprofundado os efeitos dessa substância no organismo dos indivíduos infectados.

\section{REFERÊNCIAS}

BARBOSA, Kiriaque Barra Ferreira et al. Oxidative stress: concept, implications and modulating factors. Rev. Nutr., Campinas, v. 23, n. 4, p. 629-643, jul./ago. 2010. Disponível em http://www.scielo.br/pdf/rn/v23n4/v23n4a13. Último acesso em 06/04/2020.

BAUM, Marianna; SHOR-POSNER, Gail; CAMPA, Adriana. Zinc status in human immunodeficiency virus infection. J. Nutr. [online], v. 130, issue 5, p. 1421S-1423S; Mai. 2000. Disponível em https://academic.oup.com/jn/article/130/5/1421S/4686400. Último acesso em 06/04/2020.

BIAGOLI, Rosângela Elaine Mineo. Tuberculose em foco. São Paulo: Cortez, 2008.

BOCKOR, Luciane. Indicadores bioquímicos do status nutricional. Seminário. Programa de Pós-Graduação em Ciências da Universidade Federal do Rio Grande do $\begin{array}{llll}\text { Sul. } & 23 p . & 2010 . & \text { Disponível }\end{array}$ https://www.ufrgs.br/lacvet/restrito/pdf/indicadores_nutri_luciane.pdf. Último acesso em 06/04/2020.

BONHAM, Maxine et al. The Immune System as a Physiological Indicator of Marginal Copper Status? Br J Nutr. [online], v. 87, n. 5, p. 393-403, Mai. 2002. Disponível em https://www.cambridge.org/core/services/aop-cambridgecore/content/view/S0007114502000739. Último acesso em 06/04/2020.

BRASIL. Ministério da Saúde. Secretaria de Vigilância em Saúde. Departamento de Vigilância Epidemiológica. Plano Estratégico para o Controle da Tuberculose, Brasil 2007-2015. Brasília: Ministério da Saúde, 2006. Disponível em 
https://www.paho.org/bra/index.php?option=com_docman\&view=download\&category _slug=tuberculose-971\&alias=927-plano-estrategico-para-o-controle-da-tuberculosebrasil-2007-2015-7\&Itemid=965. Último acesso em 06/04/2020.

BRASIL. Ministério da Saúde. Secretaria de Vigilância em Saúde. Programa Nacional de Controle da Tuberculose. Departamento de Vigilância das Doenças Transmissíveis. Manual de Recomendações para o Controle da Tuberculose no Brasil. Brasília: Ministério da Saúde, 2019. Disponível em https://www.paho.org/bra/index.php?option=com_docman\&view=download\&alias=10 42-manual-recomendacoes-para-o-controle-da-tuberculose-no-brasil$2 \&$ category_slug=tuberculose-971\&ltemid=965. Último acesso em 06/04/2020.

CARDOSO, Marly Augusto. Série Nutrição e Metabolismo. São Paulo: Guanabara Koogan, 2007.

CHANDRA, Ranjit Kumar. Excessive Intake of Zinc Impairs Immune Responses. J. Am. Med. Assoc. [online], v. 252, p. 1443-46, set. 1984. Disponível em https://www.ncbi.nlm.nih.gov/pubmed/6471270. Último acesso em 06/04/2020.

COMINETTI, Cristiane; REIS, Bruna Zavarize; COZZOLINO, Silvia Maria Franciscato. 2. ed. São Paulo: ILSI Brasil-International Life Sciences Institute do Brasil, 2017.

CORDOVA, Álvarez; ALVAREZ-MON, Merlchor. Behaviour of Zinc in Physical Exercise: A Special Reference to Immunity and Fatigue. Neurosci and Biobehav Rev. [online], v. 19, n. 3, p. 439-45, Set. 1995. Disponível em https://www.semanticscholar.org/paper/Behaviour-of-zinc-in-physical-exercise\%3AA-special-C\%C3\%B3rdova-AlvarezMon/575e047d8fb5bd7e50cf6da07590bde802d5fcc9. Último acesso em 06/04/2020.

DONANGELO, Carmen. Zinco, estresse oxidativo e atividade física. Rev. Nutr. [online], v. 16, n. 4, p. 433-441, dez. 2003. Disponível em http://www.scielo.br/scielo.php?pid=S141552732003000400007\&script=sci_abstract\&tIng=pt. Último acesso em 06/04/2020. 
FERNANDES, Alícia Gomes; MAFRA, Denise. Zinco e câncer: uma revisão. Revista Saúde. Com. [online], v. 1, n. 2, p. 144-156, 2005. Disponível em https://www.researchgate.net/publication/26428548_Zinco_e_cancer_uma_revisao. último acesso em 06/04/2020.

FOOD AND NUTRITION BOARD. Dietary reference intakes for vitamin A, vitamin $\mathrm{K}$, arsenic, boron, chromiun, copper, iodine, iron, manganese, molybdnum, nickel, silicon, vanadium, and zinc. Washington: National Academy of Sciences, 2001.

HARLING, Guy; CASTRO, Marcia Caldas de. A spatial analysis of social and economic determinants of tuberculosis in Brazil. J. Health \& Place, v. 25, p. 56-67, 2014. Disponível https://www.researchgate.net/publication/259158052_A_spatial_analysis_of_social_a nd_economic_determinants_of_tuberculosis_in_Brazil. Último acesso em 06/04/2020.

KING, Janet; COUSINS, Robert. Zinco. In: SHILS, Maurice Edward et al. (eds.). Tratado de nutrição moderna na saúde e na doença. V. 1. 9 Ed. São Paulo: Manole, 2003. 1690 p. p.239-56.

LEÃO, Eliana Aparecida; SANTOS JUNQUEIRA, Eliane Aparecida; MACHADO, Neale. Distribuição dos casos de Tuberculose no município de Itajubá. XII Encontro Latino Americano de Iniciação Científica e VIII Encontro Latino Americano de PósGraduação - Universidade do Vale do Paraíba, 3p., 2008. Disponível em http://www.inicepg.univap.br/cd/INIC_2008/anais/arquivosINIC/INIC1019_01_A.pdf. Último acesso em 06/04/2020.

LORENA, Analía Tomat et al. Zinc restriction during different periods of life: Influence in renal and cardiovascular disease. Nutrition [online], v. 27, issue 4, p. 392-398, abr. 2011.

https://www.sciencedirect.com/science/article/abs/pii/S0899900710003412. Último acesso em 06/04/2020. 
MACIEL, Marina de Souza et al. A história da tuberculose no Brasil: os muitos tons (de cinza) da miséria. Rev. Bras. Clin. Med. São Paulo [online], v. 10, n. 3, p. $226-$ 230 mai.-jun. 2012. Disponível em http://files.bvs.br/upload/S/16791010/2012/v10n3/a2886.pdf. Último acesso em 06/04/2020.

MAFRA, Denise; COZZOLINO, Sílvia Maria Franciscato. Importância do zinco na nutrição humana. Revista de Nutrição [online], v.17, p. 79-87, jan./ mar. 2004. Disponível em http://www.scielo.br/pdf/rn/v17n1/a09v17n1.pdf. Último acesso em 06/04/2020.

MARQUES, Raynerio Costa; MARREIRO, Dilina do Nascimento. Metabolic and functional aspects of zinc in Down syndrome. Revista de Nutrição, Campinas, n.4, v.19, p. 501-510, jul./ago. 2006. Disponível em http://www.scielo.br/pdf/rn/v19n4/a09v19n4.pdf. Último acesso em 06/04/2020.

METCALFE, Neil. A study of tuberculosis, malnutrition and gender in Sri Lanka. Transactions of the Royal Society of Tropical Medicine and Hygien [online], v. 99, n. 2, p. 115-119, Mar. 2005. Disponível em https://www.researchgate.net/publication/8123377_A_study_of_tuberculosis_malnutri tion_and_gender_in_Sri_Lanka. Último acesso em 06/04/2020.

MINISTÉRIO DA SAÚDE. www.portaldasaúde.com.br. Último acesso em 06/04/2020.

MOCCHEGIANI, Eugenio; MUZZIOLI, Mario; GIACCONI, Robertina. Zinc and immunoresistance to infection in aging: new biological tools. Trends Pharmacol Sci. [online], v. 21, n. 6, p. 205-8, jun. 2000. Disponível em https://www.ncbi.nlm.nih.gov/pubmed/10838605. Último acesso em 06/04/2020.

NOGUEIRA, Carla Ribeiro et al. Aspectos antropométricos, bioquímicos e sintomatológicos em mulheres com tuberculose pulmonar. Rev. Ciênc. Méd., Campinas, v. 15, n. 4, p. 281-288, jul./ago., 2006. Disponível em https://seer.sis.puccampinas.edu.br/seer/index.php/cienciasmedicas/article/view/1098/1074. Último acesso em 06/04/2020. 
OSORIO, Rafael Guerreiro; SOARES, Sergei Suarez Dilon; SOUZA, Pedro Herculano Guimarães. Erradicar a extrema pobreza: um objetivo ao alcance do Brasil. Brasília:

IPEA, 2011.

Disponível

em https://www.ipea.gov.br/portal/index.php?option=com_content\&view=article\&id=9610 . Último acesso em 06/04/2020.

PEDERSEN, Bente Klarluund; TOFT, Anders Dyhr. Effects of exercise on lymphocytes and cytokines. Br J Sports Med. [online], v. 34, n. 4, p. 246-51, ago. 2000. Disponível em https://www.ncbi.nlm.nih.gov/pubmed/10953894. Último acesso em 06/04/2020.

POWELL, Saul. The antioxidant properties of zinc. Journal of Nutrition [online], v.130, suppl. 5, p.1447-54, Jun. 2000. Disponível em https://www.researchgate.net/publication/12515491_The_Antioxidant_Properties_of_ Zinc. Último acesso em 06/04/2020.

PRASAD, Ananda. Zinc and Immunity. Mol Cell Biochem [online], n. 188, p. 63-69, Nov. 1998. Disponível em https://www.ncbi.nlm.nih.gov/pubmed/9823012. Último acesso em 06/04/2020.

RINK, Lothar; KIRCHNER, Holger. Zinc-altered immune function and cytokine production. J. Nutr. [online], v. 130, suppl. 5, p. 1407S-11S, Mai. 2000. Disponível em https://www.ncbi.nlm.nih.gov/pubmed/10801952. Último acesso em 06/04/2020.

SHANKAR, Anuraj; PRASAD, Ananda. Zinc and immune function: The biological basis of altered resistance to infection. Am. J. Clin. Nutr. [online], v. 68, suppl. 2, p. 4.475635, ago. 1998. Disponível em https://www.ncbi.nlm.nih.gov/pubmed/9701160. Último acesso em 06/04/2020.

SINGH, Anita et al. Dietary Intakes ad Biochemical Profiles of Nutritional Status of Ultramarathoners. Med. Sci. Sports Exerc. [online], v. 25, n. 3, p. 328-334, mar. 1993. Disponível 
https://www.researchgate.net/publication/14744758_Dietary_intake_and_biochemical _profiles_of_nutritional_status_of_untramarathoners. Último acesso em 06/04/2020.

SOARES, Sergei Suarez Dillon. Metodologias para estabelecer a linha de pobreza: objetivas, subjetivas, relativas, multidimensionais. Brasília: IPEA, 2009.

TALON, Lidiana de Camargo; PEREIRA, Paulo Câmara Marques. Perfil nutricional de pacientes com tuberculose internados em enfermaria de moléstias infecciosas e parasitárias. Revista Brasileira de Nutrição Clínica [online], v. 25, p. 109-113, 2010. Disponível em http://www.braspen.com.br/home/wp-content/uploads/2016/12/03Perfil-nutricional-de-pacientes-com-tuberculose-internados-em-enfermaria-demol\%C3\%A9stias-infeccio.pdf. Último acesso em 06/04/2020.

ZUMLA, Alimuddin et al. WHO's 2013 global report on tuberculosis: successes, threats, and opportunities. The Lancet [online], v. 382, p. 1765-1767, nov. 2013. Disponível em http://www.who.int/tb/publications/global_report/en/. Último acesso em 06/04/2020.

\section{APÊNDICE - REFERÊNCIA DE NOTA DE RODAPÉ}

2.

http://www.inicepg.univap.br/cd/INIC_2008/anais/arquivosINIC/INIC1019_01_A.pdf 


\section{ANEXOS}

ANEXOS A-Tabela 1: Pontos de corte para zinco sérico.

Table 1. Cutoff points for serum Zinc

\begin{tabular}{|c|c|c|}
\hline life stages & Zn serum (female) $(\mu \mathrm{g} / \mathrm{dL})$ & Zn serum (male) $\quad(\mu \mathrm{g} / \mathrm{dL})$ \\
\hline$<10$ years* & 64 & 65 \\
\hline$>10$ years $* *$ & 70 & 74 \\
\hline$>65$ years** & 72 & 72 \\
\hline \multicolumn{3}{|c|}{ gestation } \\
\hline First trimester $* *$ & 56 & - \\
\hline Second trimester $* *$ & 50 & - \\
\hline Third trimester $* *$ & 50 & - \\
\hline \multicolumn{3}{|c|}{ women using contraceptive } \\
\hline $20-44$ years** & 65 & - \\
\hline
\end{tabular}

* blood samples collected in the morning, without fasting

** blood samples collected in the morning, with fasting.

Source: Hotz et al. (2003).

Fonte: Hotz et al. (2003, apud COMINETTI; COZZOLINO; REIS, 2017, p. 18)

ANEXO B- Tabela 2: Ações e mecanismos de algumas substâncias antioxidantes.

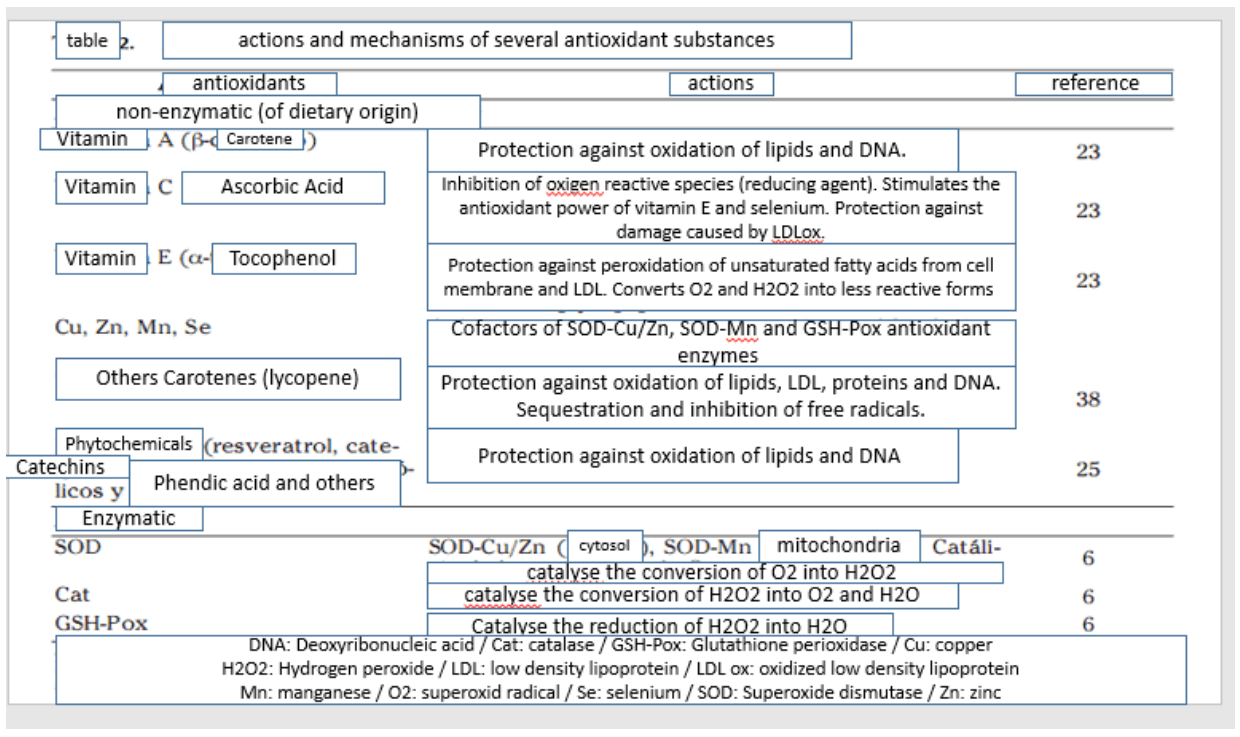

Fonte: Barbosa et al. (2010, p. 635) 
ANEXO C- Figura 1: Relação do zinco com o estresse oxidativo e processo inflamatório.
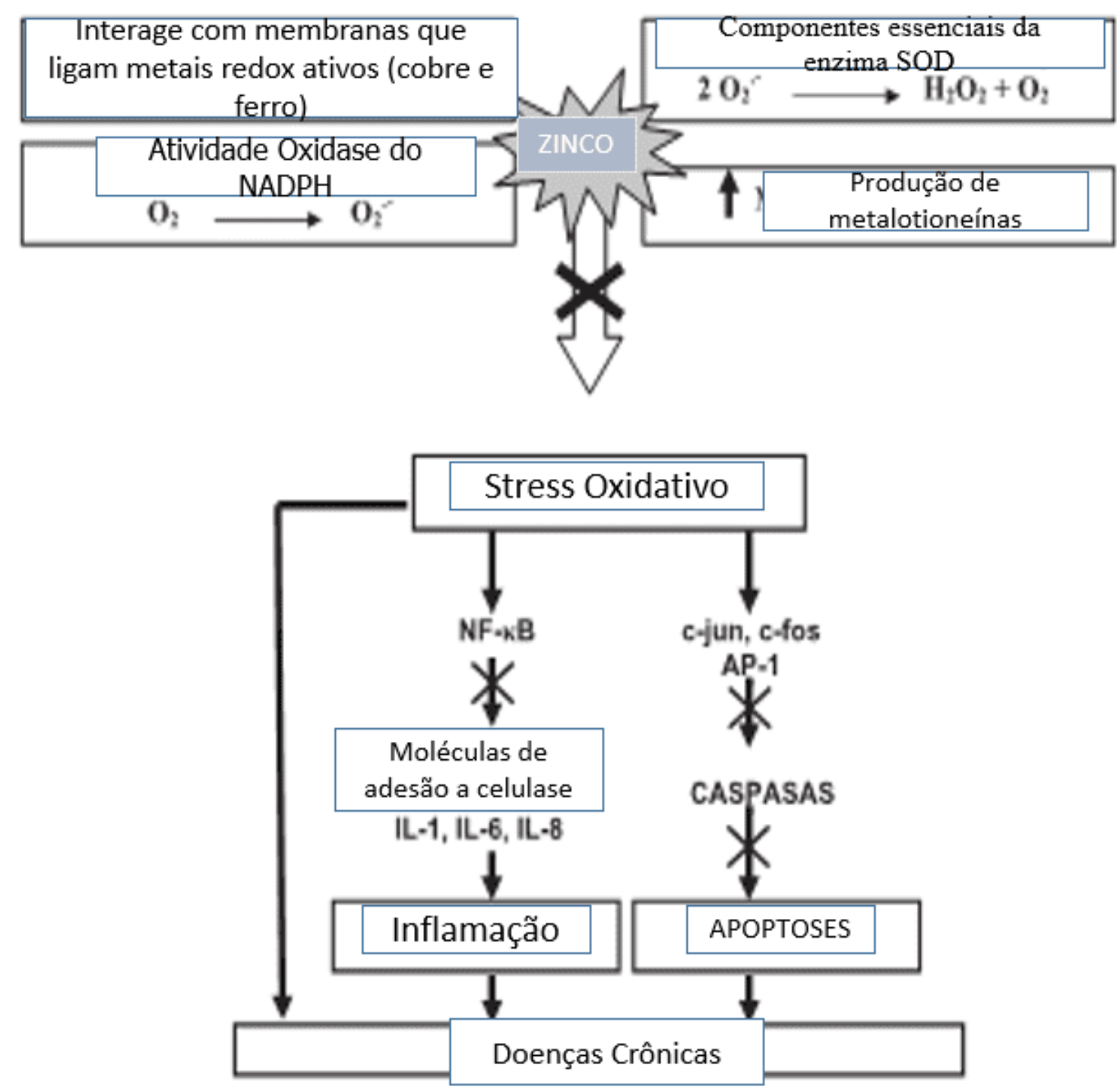

Fonte: LORENA (2011, p. 394).

Enviado: Março, 2020.

Aprovado: Abril, 2020. 